and it does seem as though in certain carefully well selected cases we should possess definite information as to how much or how little drugs are factors. It would not be difficult in functional diseases to determine this factor; but in self-limited diseases the problem is a different one. Homeopathy has won its successes in the treatment of epidemic disorders, and we point with pride to those statistics so long ago offered by Fleischman in the successful treatment of pneumonia. The time has come and is not far distant when such tests of the remedial power of homeopathic drugs as shall silence all doubt will be made. It is the truth that we seek; selfdeception must not longer rule us, and suffering humanity will be the gainer. The weakness of homeopathy lies in the crude and imperfect application of its principles, and in that most important defect, lack of entire faith in its adaptability. Polypharmacy in the minds of most of the new school is an anachronism, a thing not to be tolerated; and yet with us it is even now a menacing evil. This, gentlemen, is not homeopathy, give it some other name if you wish to adopt it; but leave to us the single remedy and the approval of an honest mind. As Dr. Elbridge C. Price has well said: " Do not forget, however, that since the days when Hahnemann wrote his ' Organon,' the world has progressed, arts have become more vital and effective, and the ever-multiplying branches of science have evolved into varied systems of learning of which the sages of the eighteenth century could have no conception. Do not forget that it is quite possible for many of the unessentials which have grown up beside the vital law, to be proven to be without foundation in fact, and that it is unHahnemannian in men of to-day to refuse to recognize the demonstrable facts of science. And finally, do not forget that nothing ever yet has modified in the slightest the truth of that eternal verity, the law of similars, and, to judge from the sublime verdict of the ages, nothing ever will. Its roots dip deep beneath the dust of remotest antiquity, and its branches reach out into the empyrean of coming time, bearing its leaves to all the ends of the earth for the healing of all the unborn nations of all futurity."

\section{AN INEXPENSIVE MECHANICAL TREATMENT FOR ANTERIOR METATARSALGIA.}

BY ERNEST BOYEN YOUNG, M.D., BOSTON,

Second Assistant Visiting Physician for Diseases of Women, Boston City Hospital; Assistant in Gynecology, Harvard Medical School.

OR'SHOPEDIC surgery and gynecology would seem, at first glance, to be almost too widely separated in their scope to have any interdependence; but there is a class of cases, coming, as a rule, to the specialist in diseases of women, in which pain is referred to the pelvis, lower back and hips, for which pelvic examination shows no adequate cause. Poor muscular development and improper shoes have seemed to be very often at the bottom of these difficulties. As a conse- quence, faulty methods of standing and walking, induced by the attempt to gain relief, have usually been manifest.

Some of these have been entirely relieved by suitable shoes and education as to the proper methods of standing; and others by muscular exercises of various kinds. Among those with indefinite pains about the pelvis have been a number suffering from lowering of the anterior transverse arch of the foot.

In experimenting to convince myself that the pains were not of pelvic origin, the discomforts due to the breaking down of the transverse arch have been relieved by such simple devices; that it seems worth while to publish them, in order that others may have the benefit; if they prove as satisfactory in their hands, as in my own.

The inside sole and plate are both somewhat costly, and often necessitate the purchase of larger shoes, in order that they may be worn with comfort. The method adopted in my own cases does away with these drawbacks, and will be found acceptable to many of moderate means.

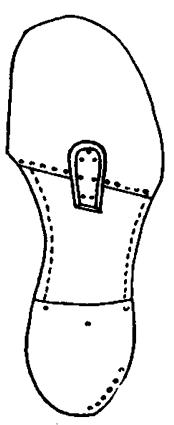

Fig. I

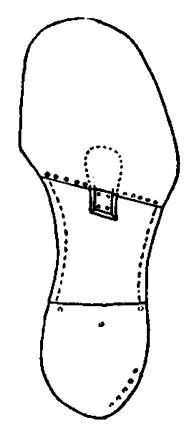

Figll

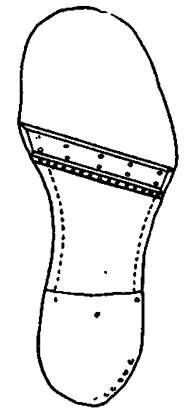

Ig III

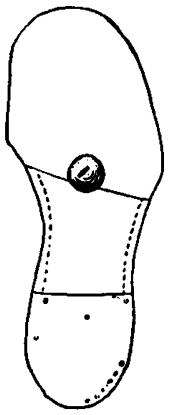

nig. IV
Diagram of different methods of applying support.

A piece of sole leather of the thickness required is cut into the shape indicated in the illustration (Fig. 1). The edges are beveled, and the leather is touched on one side with a few drops of liquid glue. It is then placed on the sole of the boot, to which it adheres, in about the required position, $i . e$., so that its pressure is exerted just behind the heads of the metatarsal bones. The situation in which it gives relief is marked with pencil, and the leather nailed in position by a shoemaker. It can also be inserted under the sole (Fig. 2), by raising the posterior edge of the sole and nailing it again in place.

If there is too much pressure, the leather is pared to the requisite thickness, as indicated by the comfort of the wearer.

The increased depth, at the point where the leather is inserted, raises the sole over this area and slightly beyond, whenever the patient steps this in turn supporting the anterior arch.

Experiments have also been made with the leather and rubber buttons (Fig. 4) which are manufactured for use upon the bottoms of chair legs. While they answer the purpose when screwed to the bottom of the shoe, they are not so firm, and distributing the pressure over a smaller area, are less comfortable than the leather 
tongue. However, they will be found useful occasionally, as they can be fitted in the office by the same methods as the leather tongue, and fixed in place immediately upon any thick-soled shoe. It is always necessary to shorten the screws somewhat, in order not to perforate the bottom of the boot. It is also possible to pare them down after they are in position, until the pressure exerted is acceptable to the patient. Still another means of accomplishing the same result, and one which is especially applicable to shoes which are to withstand severe wear, is shown in Jig. 3. The leather strip raises all the metacarpals slightly, and, at the same time, by varying the angle at which it is placed on the shoe, it may be made to aid in raising the inner side of a pronated foot. In mild cases this works exceedingly well. The proper slant and thickness are adjusted to the comfort of the patients as they stand upon the leather strip. Naturally, suitable exercises should be carried out in every case.

Suffering from metatarsalgia I have tested these different methods upon myself, with relief, and, therefore: feel that I can recommend them from personal experience. They are not advocated for all types; but it is possible by these means to give relief to many at a moderate cost, who would find the purchase of new shoes, plates and pads a strain upon their small financial resources.

\section{Bogton elitn ogpital.}

\author{
CLINICAL MEETING, JAN. 11, 1906.
}

Dr. Henry Jackson, chairman, Dr. L. R. G. Crandon, secretary.

\section{DISLOCATION OF SHOULDER WITH CONTUSION OF BRACHIAL PLEXUS.}

BY L. R. G. CRANDON, M.D.

A MAN of fifty-four years fell sideways to the ground, striking on his right elbow. He came to the hospital to complaining of the usual disability of shoulder dislocation, together with numbness of the hand and fingers.

Examination showed a subcoracoid dislocation of the right shoulder with paresis and numbness of right hand.

The shoulder was easily reduced by the Kocher method at the first attempt. The evidences of nerve injury continued, namely, wrist drop, entire loss of all finger motions, anesthesia over the whole "glove" area, and partial anesthesia over front and back of forearm and of anterior aspect of arm.

Diagnosis: Contusion of part of brachial plexus.

At the end of one month, having received electricity and massage, condition is considerably improved, but the power of the hand is far from being normal.

This case has great medico-legal value, in my opinion, since, if a careful physical examination at the time of entrance had not been made it might have been concluded, to the detriment of the operator, that the manipulations of reduction had caused the nerve injury.
FIBROIDS AND PREGNANCY, EXTRA- AND INTRAUTERINE PREGNANCY.

BY ERNEST B. YOUNG, M.D.

I. A case in which delivery by version, on account of eclampsia, was obstructed by multiple fibroids. The mother recovered, although there was some disturbance of the circulation of the tumors, and the premature child survived.

II. Specimens from a case of coincident extraand intra-uterine pregnancy. The extra-uterine pregnancy ruptured and patient was operated upon for relief of hemorrhage. Pregnancy advanced to about the sixth week.

A TUMOR OF THE KIDNEY SHOWN BY MICROSCOPIC EXAMINATION TO BE HYPERNFPHROMA.

BY J. C. HUBBARD, M.D.

W. G., male, fifty-six years old; married.

Family History. - Father died of old age at eightyfour. Mother at fifty-five from some injury to her side. Two sisters at about thirty-five who had both been sick about two years. One sister and three brothers alive and well.

Previous history: Patient, when young was not considered healthy but was always, nevertheless, able to do hard work. Has had no sickness of any consequence or venereal disease. For a period previous to nine years ago was at intervals a hard drinker.

Present illness: Two years ago last April was seized with a sudden pain in right side severe enough to double him up. The attack was followed immediately by blood in the urine. From this time has had attacks of bloody urine at intervals. At first every four or five weeks but steadily growing more frequent. Sometimes they were accompanied by pain sometimes not. At first the blood lasted for a day or two. With the succeeding attacks it lasted longer and longer, a week at a time. Has had at times difficulty in passing urine from clogging of the urethra with blood clots. There has been no especial loss of weight noticed. Feels somewhat weaker than usual.

Physical examination: Well developed and nourished man. Radial artery somewhat hard but the pulse tension not high. An enlarged lymph gland in right axilla, otherwise no increase in the size of the superficial glands. Chest negative. Liver dullness extended from the fourth space in the mammary line to two fingers' breadth below the rib margin. Its edge was plainly palpable, not irregular. Spleen and left kidney not palpable. Hemoglobin $90 \%$. In the region of the right kidney there was a firm, evenly rounded tumor, moving with respiration independently of the liver. Feels similar to the kidney in shape but larger. Not tender. No other tumor masses felt in the abdomen.

Urine passed immediately after the examination was almost pure blood. That examined several days later was as follows: Acid, color normal, 1018, albumin large trace to $1-10 \%$, sugar absent. Microscopic examination of the sediment: Much blood, normal or only slightly abnormal; few leucocytes; many round cells slightly larger than leucocytes; many with several nuclei of fat drops: no crystals or casts.

Operation: Ether.

Patient was placed on left side on pillow. The incision ran from the outer part of the twelfth rib parallel to the spine down to the crest of the ilium. The perirenal fat, which was of small amount, was opened, and the kidney freed with the hand. There were a number of adhesions which were broken by the hand. The hemorrhage was very free but it never 